Original Article

\title{
Differences in physical activity between seasons with and without snowfall among elderly individuals residing in areas that receive snowfall
}

\author{
Shunichi Ogawa, PT, MS ${ }^{1 *}$, Toshiaki Seko, PT, $\mathrm{MS}^{1)}$, Toshikazu Ito, PT, $\mathrm{PhD}^{1)}$, \\ Mitsuru Mori, $\mathrm{MD}, \mathrm{PhD}^{1)}$ \\ 1) Hokkaido Chitose College of Rehabilitation: 2-10 Satomi, Chitose, Hokkaido 066-0055, Japan
}

\begin{abstract}
Purpose] This study aimed to examine the influence of climatic conditions on the daily physical activities of elderly individuals by comparing the physical activity during seasons with and without snowfall. [Participants and Methods] In total, 35 participants attending the Health Promotion Program conducted by Chitose City Office participated in this study. The survey for the seasons with snowfall was conducted in February 2016, while the survey for the seasons without snowfall was conducted in September 2015. The physical activity of the participants was measured using a Kenz Lifecorder GS accelerometer. [Results] Physical activity was found to be significantly lower during seasons with snowfall than in seasons without snowfall. Multivariate analysis revealed that physical activity significantly increased with lower temperature during the seasons with snowfall, and it significantly increased with higher temperature and decreased with larger amounts of precipitation during the seasons without snowfall. [Conclusion] It was found that the climatic conditions affect the level of physical activity during seasons with and without snowfall. A lower level of physical activity was observed in areas that received snowfall than in areas that did not receive snowfall.

Key words: Physical activity, Season, Weather
\end{abstract}

(This article was submitted May 16, 2018, and was accepted Oct. 7, 2018)

\section{INTRODUCTION}

It is reported that an increase of physical activity is effective for prevention of chronic diseases, cognitive functional decline and mortality ${ }^{1-3)}$. A decrease in physical activity is also shown to be responsible for increasing the national economic burden ${ }^{4}$. Namely, it is thought that physical activity is important for health promotion and disease prevention.

However, physical activity is not easily increased, and is often decreased with aging ${ }^{5)}$. It has also been suggested that the climate and the other environmental influences impact physical activity, and that there is large diversity in physical activity among different climates ${ }^{5-9}$. There are four seasons in Hokkaido, the northern part of Japan, and it snows in this region in the winter. However, to our knowledge, there are few studies on differences in physical activity by season, even in snowfall areas. Therefore, we examined the influence of climatic conditions on physical activity in the daily life of the elderly, comparing physical activity in snowfall seasons with those in non-snowfall seasons.

\section{PARTICIPANTS AND METHODS}

We recruited study participants from adults aged 50 years or older who had participated in the Health Promotion Program

*Corresponding author. Shunichi Ogawa (E-mail: s-ogawa@chitose-reha.ac.jp)

(C2019 The Society of Physical Therapy Science. Published by IPEC Inc.

(c) (1) $($ This is an open-access article distributed under the terms of the Creative Commons Attribution Non-Commercial No Derivatives CC. ${ }_{\text {BY }}$ ND (by-nc-nd) License. (CC-BY-NC-ND 4.0: https://creativecommons.org/licenses/by-nc-nd/4.0/) 
Table 1. Comparison of background characteristics and physical activity in 35 study participants, and weather condition of Citose City between the snowfall and the non-snowfall seasons

\begin{tabular}{|c|c|c|c|c|}
\hline & $\begin{array}{c}\text { Snowfall } \\
\text { season }\end{array}$ & $\begin{array}{l}\text { Non-snowfall } \\
\text { season }\end{array}$ & $\begin{array}{c}\text { Difference } \\
\text { (absolute value) }\end{array}$ & p value ${ }^{\#}$ \\
\hline Age (years) & $69.3 \pm 5.3$ & $69.3 \pm 5.3$ & & \\
\hline Body height $(\mathrm{cm})$ & $155.8 \pm 6.5$ & $155.8 \pm 6.5$ & & \\
\hline Body weight $(\mathrm{kg})$ & $56.2 \pm 7.3$ & $56.4 \pm 7.0$ & & \\
\hline Body Mass Index $\left(\mathrm{kg} / \mathrm{m}^{2}\right)$ & $23.2 \pm 2.7$ & $23.2 \pm 2.7$ & & \\
\hline Average number of persons in the household & $1.4 \pm 0.9$ & $1.4 \pm 0.9$ & & \\
\hline Average number of days going out per week & $4.5 \pm 1.7$ & $4.6 \pm 1.8$ & $0.1 \pm 1.6$ & 0.600 \\
\hline Frequency of physical exercise more than 30 minutes a day & $3.4 \pm 1.7$ & $3.4 \pm 1.8$ & $0.2 \pm 1.5$ & 0.340 \\
\hline Average days wearing the Lifecorder & $28.3 \pm 1.4$ & $29.1 \pm 1.2$ & $0.8 \pm 1.8$ & 0.015 \\
\hline Average number of step counts (STEP) per day & $6,420 \pm 3,098$ & $8,127 \pm 3,677$ & $1,707 \pm 2,439$ & $<0.001$ \\
\hline Average of total energy consumption (TEA) per day (kcal) & $1,618 \pm 148$ & $1,682 \pm 195$ & $64 \pm 112$ & 0.002 \\
\hline $\begin{array}{l}\text { Average of energy consumption by physical activity (ECPA) } \\
\text { per day (kcal) }\end{array}$ & $182 \pm 82$ & $236 \pm 115$ & $47 \pm 65$ & $<0.001$ \\
\hline $\begin{array}{l}\text { Average duration of moderate and vigorous physical activity } \\
\text { (MVPA) per day (min) }\end{array}$ & $17 \pm 15$ & $22 \pm 22$ & $6 \pm 11$ & 0.007 \\
\hline Average temperature $\left({ }^{\circ} \mathrm{C}\right)$ & $-4.1 \pm 3.9$ & $17.0 \pm 2.4$ & $21.2 \pm 0.8$ & $<0.001$ \\
\hline Average wind velocity (m/s) & $3.6 \pm 1.7$ & $3.1 \pm 1.0$ & $0.5 \pm 0.6$ & 0.117 \\
\hline Average precipitation (mm) & $0.0 \pm 0.0$ & $6.0 \pm 20.0$ & & \\
\hline Average snowfall $(\mathrm{cm})$ & $2.6 \pm 4.5$ & $0.0 \pm 0.0$ & & \\
\hline
\end{tabular}

Mean \pm standard deviation. ${ }^{*}$ Paired t-test.

provided by Chitose City Office. Exclusion criteria of participants in the study was severe diseases, such as psychiatric disorders, and orthopedic diseases, stroke, pain. Eventually, 35 participants (12 males, 23 females) participated in this study, for the participants the average age was $69.3 \pm 5.3$ years, the average height was $155.8 \pm 6.5 \mathrm{~cm}$, and the average weight was $56.2 \pm 7.3 \mathrm{~kg}$. Written informed consent following full explanation of the study was obtained from each study participant. The Ethics Committee of Sapporo Medical University approved this study (Approval Number: 27-2-4).

A questionnaire was administered twice to the study participants and was used for measuring their personal physical activity characteristics one month prior to the survey, in September of 2015, and again January of 2016. The following items were included in a questionnaire; age, body height, body weight, BMI, the number of persons in the household, the number of days going outside per week, and frequency of physical exercise greater than 30 minutes a day using 6 choices such as, more than three times a week (5), more than twice a week (4), once a week (3), twice or three times a month (2), once a month (1), and less than once a month or none $(0)$.

Their physical activity was measured with a Kenz Lifecorder GS (Suzuken Co., Ltd., Nagoya, Japan) accelerometer. The items measured with this device were as follows; the daily step count (STEP), total energy consumption (TEA) per day (kcal), energy consumption by physical activity (ECPA) per day ( $\mathrm{kcal}$ ), and duration ( $\mathrm{min}$ ) of moderate and vigorous physical activity (MVPA). TEA per day is figured out as a summation of ECPA per day and energy consumption by basic metabolism per day.

This device is utilized by attaching it to a person's waist. It is advised to use the device during all waking hours, except for bathing, and to live as routine a life as possible. We adopted the previously proposed criteria ${ }^{10,11)}$ for daily use which was to wear the device for more than or equal to 10 hours. The survey was conducted both in February of 2016 for the snowfall season, and September of 2015 for the non-snowfall season.

We collected information about weather conditions such as temperature, wind velocity, precipitation, and snowfall in Chitose City both in September 2015, and, February 2016 from the website of the Japan Meteorological Agency.

We used the paired t-test, the Spearman's rank correlation, and a multiple linear regression analysis for the statistical analysis. SPSS version 23.0 was applied for every analysis. The level of significance set up at 5\%.

\section{RESULTS}

Table 1 shows the comparison of background characteristics and physical activity in 35 study participants, and the weather conditions of Chitose City between the snowfall and non-snowfall seasons. The average number of days that study participants went outdoors per week, as well as the frequency of physical exercise of more than 30 minutes a day, was not different between the snowfall and the non-snowfall season. The average days (standard deviation, or SD) wearing the Lifecorder 
during the snowfall season and the non-snowfall season were 28.3 days (1.4) in February, and 29.1 days (1.2) in September, respectively.

The average step count (STEP) was significantly less in the snowfall season $(6,420)$ than in the non-snowfall season $(8,127)$ with a difference of $1,707(\mathrm{p}<0.001)$. Similarly, the average of total energy consumption (TEA) per day was significantly less in the snowfall season $(1,618 \mathrm{kcal})$ than in the non-snowfall season $(1,682 \mathrm{kcal})$ with a difference of $64 \mathrm{kcal}$ $(\mathrm{p}=0.002)$. The average energy consumption by physical activity (ECPA) per day was also significantly less in the snowfall season $(182 \mathrm{kcal})$ than in the non-snowfall season $(236 \mathrm{kcal})$ with a difference of $47 \mathrm{kcal}(\mathrm{p}<0.001)$. In addition, duration of moderate and vigorous physical activity (MVPA) was significantly less in the snowfall season (17 min) than in the nonsnowfall season $(22 \mathrm{~min})$ with a difference of $6 \mathrm{~min}(\mathrm{p}=0.007)$.

The average temperature (standard deviation) of the snowfall and non-snowfall seasons in Chitose City was $-4.1^{\circ} \mathrm{C}$ (3.9) and $17.0^{\circ} \mathrm{C}(2.4)$, respectively $(\mathrm{p}<0.001)$. The average wind velocity was not different between the snowfall and the non-snowfall seasons in Chitose City.

As shown in Table 2, all of the Spearman's rank correlation coefficients (rs) of STEP, TEA ECPA, and MVPA between the snowfall and the non-snowfall seasons were significant, and the rs figures ranged from 0.42 to 0.89 .

Table 3 shows the Spearman's rank correlation coefficient (rs) between physical activity in 35 study participants and weather condition in Chitose City both in the snowfall and the non-snowfall seasons. During the snowfall season, snowfall was significantly positively correlated with STEP $(\mathrm{rs}=0.46, \mathrm{p}<0.05)$, and temperature was significantly negatively correlated with MVPA ( $\mathrm{rs}=-0.44, \mathrm{p}<0.05)$. In the non-snowfall season, temperature was significantly positively correlated with STEP $(\mathrm{rs}=0.37, \mathrm{p}<0.05)$, precipitation was significantly negatively correlated with STEP $(\mathrm{rs}=-0.47, \mathrm{p}<0.01)$, and precipitation was significantly negatively correlated with MVPA ( $\mathrm{rs}=-0.42, \mathrm{p}<0.05)$.

Table 4 shows the results of the multiple linear regression analysis on association between physical activity and weather condition. During the snowfall season, temperature was significantly negatively associated with STEP $(\mathrm{p}=0.030)$, as well as with MVPA $(\mathrm{p}=0.041)$. During the non-snowfall season, temperature was significantly positively associated with STEP $(p=0.019)$, precipitation was significantly negatively associated with STEP $(p=0.014)$ as well as with MVPA $(p=0.038)$.

\section{DISCUSSION}

Physical activity such STEP, TEA, ECPA, and MVPA measured with an accelerometer was found to be significantly less during the snowfall season than during the non-snowfall season. Furthermore, it was found that physical activity increased with lower temperature during the snowfall season, and that physical activity increased with higher temperature and decreased with larger amount of precipitation in the non-snowfall seasons.

Yasunaga et al. ${ }^{5)}$ conducted a survey of Japanese elderly aged between 65-83 years, using an accelerometer. Similar to our study, they showed that step count and amounts of physical activity were low in the winter, and peaking in spring and autumn. Wagner et al. ${ }^{6}$ examined the association between weather conditions and outdoor exercise with a survey using a structured questionnaire, and they found that the study participants delayed outdoor exercise in winter, as compared to other seasons. Merrill et al. ${ }^{7}$ also reported that season significantly influenced physical activity, with the highest percentage of adults meeting the recommendations for physical activity during summer and the lowest during winter.

We found that physical activity increased with lower temperature in the snowfall season, and, Mizumoto et al. ${ }^{8)}$ also reported that step counts significantly increased during midwinter compared with early winter in the group maintaining their frequency of outdoor excursions. For relatively healthy people, lower temperatures in midwinter may activate behavior such as going out and walking around their home.

Similar to our results, Togo et al. ${ }^{9)}$ found that step counts per day decreased exponentially with increasing precipitation among the study participants. Wagner et al. $\left.{ }^{6}\right)$ also showed that rain in the summer was the predominant adverse weather condition causing a reduction in outdoor exercise. However, unlike our results, they $\left.{ }^{6}\right)$ found that snow in the winter was also the predominant weather condition causing a reduction in outdoor exercise. In our study, the amount of snowfall was found to be positively correlated with physical activity in the snowfall season, although it became insignificant with the multivariate analysis. Our finding would be, in part, interpreted as follows. Because physical activity in the snowfall season was reported to be associated with the presence or absence of snow shoveling ${ }^{12)}$, snowfall may increase physical activity due to snow shoveling or housework during the snowfall season.

The daily step counts are recommended to be greater than $8,000^{13,14)}$, and the daily duration of MVPA is recommended to be greater than $20 \mathrm{~min}$ (150 min per week) by the $\mathrm{WHO}^{15}$ ). The average physical activity of our study participants were shown to be above the recommended levels in the non-snowfall season, but below the recommended levels in the snowfall season. Individual physical activity during the snowfall season was shown to be strongly correlated with those in the nonsnowfall season in our study. Therefore, it would be thought that intervention with the aim of increasing individual physical activity in the non-snowfall season may also increase physical activity in the snowfall season, and vice versa.

The strength of our study is that the physical activity of the study participants was measured with an accelerometer. Self-judgment for MVPA has been suggested to be underestimated, according to Canning et $\mathrm{al}^{16)}$. However, there are several limitations in our study. Because the study participants might be relatively healthier, it is not possible to generalize our results to the all adults living in the snowfall area. Since we did not include sufficient lifestyle or psychological factors in our study, it 

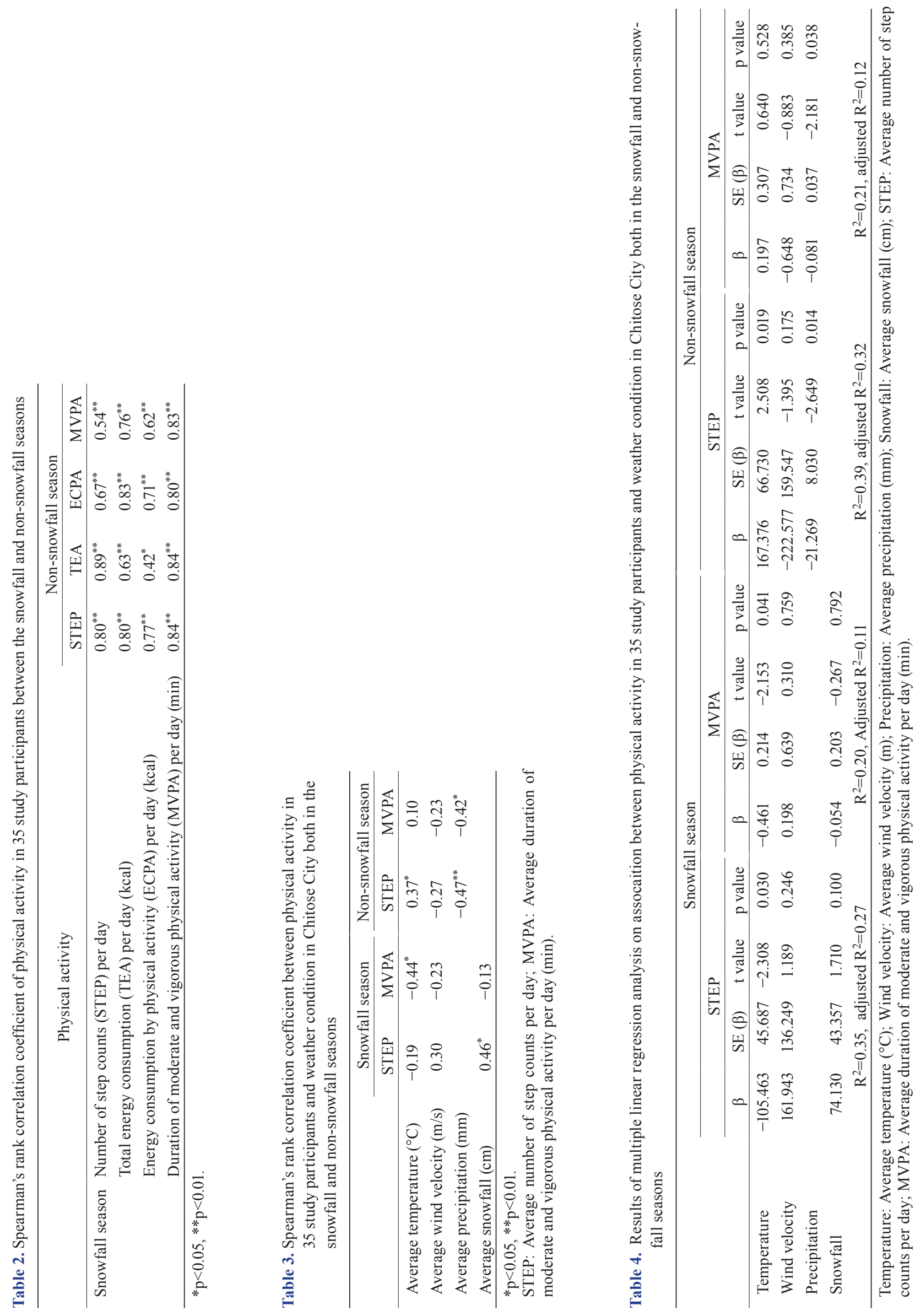
is necessary to consider those factors in a future study. Although physical activity was measured with one axial accelerometer in our study, it is known that this device has a low measurement accuracy during less intensive activities such as housework. Three axial accelerometers would be recommended to be used in the future study, because of higher accuracy in the less intensive activity ${ }^{17}$. Regarding further limitation of this study, the survey was conducted only in one area, once in September and February, and in volunteers aged 50 years old or over. Accordingly, a longitudinal study is needed in various areas and across several years, and in persons randomly selected from different age classes. Due to the small sample size in our study, it would be also required to examine a larger number of study participants in the future.

Physical activity such STEP, TEA, ECPA, and MVPA measured with a Kenz Lifecorder was found to be significantly reduced in the snowfall season compared to the non-snowfall season. Furthermore, it was found that physical activity significantly decreased with lower temperature in the snowfall season, and that physical activity significantly increased with higher temperature and decreased with larger amounts of precipitation in the non-snowfall seasons. Individual physical activity in the snowfall season was shown to be strongly correlated with those in the non-snowfall season. In conclusion, it was found that climates affect the level of physical activity in the snowfall and non-snowfall seasons, and the level of physical activity was reduced during the snowfall season as compared to the non-snowfall season.

\section{Conflict of interest}

The authors have no conflicts of interest relevant to this article.

\section{ACKNOWLEDGEMENTS}

We are grateful to the staff of the Chitose City Office for their assistance in this study. This study was supported in part by a grant from Sapporo Medical University.

\section{REFERENCES}

1) Physical Activity Guidelines Advisory Committee Report. https://health.gov/paguidelines/report/pdf/CommitteeReport.pdf\#search=\%27Physical+Activity + Guidelines+Advisory+Committee $\%$ EF\%BC\% $\%$ CPhysical+Activity + Guidelines + Advisory+Committee+Report.+U.S. + Department + of + Health + and + Huma $\mathrm{n}+$ Services $+2008 \% \mathrm{EF} \% \mathrm{BC} \% 8 \mathrm{E} \% 27$ (Accessed Apr. 5, 2018)

2) Warburton DE, Nicol CW, Bredin SS: Health benefits of physical activity: the evidence. CMAJ, 2006, 174: 801-809. [Medline] [CrossRef]

3) Ekelund U, Steene-Johannessen J, Brown WJ, et al. Lancet Physical Activity Series 2 Executive Committe Lancet Sedentary Behaviour Working Group: Does physical activity attenuate, or even eliminate, the detrimental association of sitting time with mortality? A harmonised meta-analysis of data from more than 1 million men and women. Lancet, 2016, 388: 1302-1310. [Medline] [CrossRef]

4) Ding D, Lawson KD, Kolbe-Alexander TL, et al. Lancet Physical Activity Series 2 Executive Committee: The economic burden of physical inactivity: a global analysis of major non-communicable diseases. Lancet, 2016, 388: 1311-1324. [Medline] [CrossRef]

5) Yasunaga A, Togo F, Watanabe E, et al.: Sex, age, season, and habitual physical activity of older Japanese: the Nakanojo study. J Aging Phys Act, 2008, 16: 3-13. [Medline] [CrossRef]

6) Wagner AL, Keusch F, Yan T, et al.: The impact of weather on summer and winter exercise behaviors. J Sport Health Sci, $2016,22:$ 1-7.

7) Merrill RM, Shields EC, White GL Jr, et al.: Climate conditions and physical activity in the United States. Am J Health Behav, 2005, 29: 371-381. [Medline] [CrossRef]

8) Mizumoto A, Ihira H, Makino K, et al.: Physical activity changes in the winter in older persons living in northern Japan: a prospective study. BMC Geriatr, 2015, 15: 43. [Medline] [CrossRef]

9) Togo F, Watanabe E, Park H, et al.: Meteorology and the physical activity of the elderly: the Nakanojo study. Int J Biometeorol, 2005, 50: 83-89. [Medline] [CrossRef]

10) Edwardson CL, Gorely T: Epoch length and its effect on physical activity intensity. Med Sci Sports Exerc, 2010, 42: 928-934. [Medline] [CrossRef]

11) Mâsse LC, Fuemmeler BF, Anderson CB, et al.: Accelerometer data reduction: a comparison of four reduction algorithms on select outcome variables. Med Sci Sports Exerc, 2005, 37: S544-S554. [Medline] [CrossRef]

12) Chan CB, Ryan DA: Assessing the effects of weather conditions on physical activity participation using objective measures. Int J Environ Res Public Health, 2009, 6: 2639-2654. [Medline] [CrossRef]

13) Paffenbarger RS Jr, Hyde RT, Wing AL, et al.: Physical activity, all-cause mortality, and longevity of college alumni. N Eng1 J Med, 1986 , 314: 605-613. [Medline] [CrossRef]

14) Aoyagi Y, Shephard RJ: Habitual physical activity and health in the elderly: the Nakanojo Study. Geriatr Gerontol Int, 2010, 10: S236-S243. [Medline] [CrossRef]

15) World Health Organization: Global recommendations on physical activity for health 2010. http://whqlibdoc.who.int/publications/2010/9789241599979_eng. pdf. (Accessed May 5, 2018)

16) Canning KL, Brown RE, Jamnik VK, et al.: Individuals underestimate moderate and vigorous intensity physical activity. PLoS One, 2014, 9: e97927 [CrossRef]. [Medline]

17) Ohkawara K, Oshima Y, Hikihara Y, et al.: Real-time estimation of daily physical activity intensity by a triaxial accelerometer and a gravity-removal classification algorithm. Br J Nutr, 2011, 105: 1681-1691. [Medline] [CrossRef] 